\title{
PRÁXIS, EXTENSÃO UNIVERSITÁRIA E O DESENVOLVIMENTO DE UMA CONSCIÊNCIA POLÍTICA
}

\section{ALISSON SILVA DA COSTA ${ }^{1}$, NATHÁLIA BARROS RAMOS ${ }^{2}$, PRISCILA BASTOS BRAGA DOS SANTOS ${ }^{3}$}

\author{
1Pedagogo e Mestre em Educação pela Universidade de Brasília-UnB, Professor da Secretaria de Estado e \\ Educação do Distrito Federal; \\ 2Pedagoga e Mestre em Educação pela Universidade de Brasília-UnB, Professora da Secretaria de Estado \\ e Educação do Distrito Federal; \\ 3Pedagoga pela Universidade Federal Fluminense-UFF e Mestranda em Educação pela Universidade de \\ Brasília-UnB.
}

\section{RESUMO}

A extensão universitária configura-se como instrumento de um processo dialético entre a teoria e a prática, promovendo, através da interdisciplinaridade de suas ações, uma visão integrada do social. Este trabalho objetiva analisar, a partir do currículo, a contribuição da extensão universitária para a construção da consciência política na formação inicial dos estudantes do curso de pedagogia da Universidade de Brasília (UnB). A metodologia se dará pela análise documental do Projeto Político Pedagógico Curricular do curso de pedagogia. A contribuição da extensão universitária para a construção da consciência política se dá pela relação entre universidade e sociedade, pela unidade teoria e prática, possibilitando a emancipação dos sujeitos e a transformação pessoal, social e acadêmica, ou seja, só é possível pela práxis, por uma formação que permita a apreensão dos processos históricos com todas as mediações e contradições inerentes a essa formação.

Palavras-chave:, Consciência Política; Extensão Universitária; Formação de Professores.

\section{PRAXIS, UNIVERSITY EXTENSION AND THE DEVELOPMENT OF A POLITICAL CONSCIOUSNESS}

\begin{abstract}
University extension is configured as an instrument of a dialectical process between theory and practice, promoting, through the interdisciplinarity of its actions, an integrated view of the social. This work aims to analyze, from the curriculum, the contribution of university extension to the construction of political awareness in the initial training of students in the pedagogy course at the University of Brasília (UnB). The methodology will be based on documentary analysis of the Curricular Pedagogical Political Project of the pedagogy course. The contribution of university extension to the construction of political awareness is given by the relationship between university and society, by the unity of theory and practice, enabling the emancipation of subjects and personal, social and academic transformation, that is, it is only possible through praxis,
\end{abstract}


through a formation that allows the apprehension of historical processes with all the mediations and contradictions inherent to that formation.

Keywords: Political Consciousness; Teachers Education; University Extension.

\section{INTRODUÇÃO}

Este trabalho possui como temática a relação entre extensão universitária e formação de professores, com o enfoque para a construção da consciência política nesse processo. Para a compreensão dessa relação, tentaremos identificar, se no currículo do curso de pedagogia da Universidade de Brasília (UnB), existem elementos entre a extensão universitária e a formação inicial que possibilite a construção da consciência política. Importante ressaltar que o curso passou por uma reformulação do currículo que está em transição, no entanto, essa nova versão ainda não está disponível para análise nos sítios eletrônicos da Faculdade de Educação.

Partiremos, inicialmente, da problemática da curricularização da extensão e da oficialização pelos documentos legais oficiais; dando destaque ao Plano Nacional de Educação (Lei 13.005/2014) que institui a necessidade de assegurar, no mínimo, 10\% dos créditos curriculares exigidos para a graduação em programas e projetos de extensão universitária.

No documento Política Nacional de Extensão Universitária, as atividades extensionistas estão entendidas como um mecanismo que estabelece relação direta entre a universidade e diversos setores da sociedade, possibilitando aos seus participantes uma atuação transformadora. Nesse sentido, compreendemos essa análise a partir da concepção processual-orgânica de extensão apresentada por Reis $(1993,1996)$ que se caracteriza por desenvolver ações de caráter permanente, que são inerentes ao processo formativo e a produção do conhecimento, ou seja, essa linha da extensão relaciona o ensino e a pesquisa, dentro de uma parceria político-pedagógica com a sociedade.

A metodologia adotada constitui-se em estudo bibliográfico e documental, no qual empreenderemos uma análise do documento da matriz curricular do curso de pedagogia da UnB, por meio do Projeto Acadêmico do curso. Assim, temos como objetivo analisar, a partir do currículo, a contribuição da extensão universitária para a construção da consciência política na formação inicial dos estudantes do curso de pedagogia da Universidade de Brasília (UnB). 


\title{
2 DE ONDE PARTIMOS?
}

As atividades extensionistas, de acordo com o documento da Política Nacional de Extensão Universitária, “[...] permitem o enriquecimento da experiência discente em termos teóricos e metodológicos, ao mesmo tempo em que abrem espaços para reafirmação e materialização dos compromissos éticos e solidários da Universidade Pública brasileira" (FORPROEX, 2012, p. 20). Nesse documento, a extensão universitária é entendida como um mecanismo que estabelece relação direta entre a universidade e diversos setores da sociedade, possibilitando aos seus participantes uma atuação transformadora.

Nesse aspecto, o conceito de extensão ao qual se apoia essa análise está ancorado na concepção apresentada no I Encontro de Pró-reitores de Extensão das Universidades Públicas Brasileiras (FORPROEX), realizado na UnB em 1987, e reafirmado por Reis (1993):

\begin{abstract}
A extensão universitária é o processo educativo, cultural e científico que articula o ensino e a pesquisa de forma indissociável e viabiliza a relação transformadora entre a universidade e a sociedade.

A extensão é uma via de mão-dupla, com trânsito assegurado à comunidade acadêmica, que encontrará, na sociedade, a oportunidade da elaboração da práxis de um conhecimento acadêmico. No retorno à universidade, docentes e discentes trarão um aprendizado que, submetido à reflexão teórica, será acrescido àquele conhecimento. Este fluxo, que estabelece a troca de saberes sistematizados/acadêmico e popular, terá como consequência: a produção de conhecimento resultante do confronto com a realidade brasileira e regional; e a democratização do conhecimento acadêmico e a participação efetiva da comunidade na atuação da universidade (FORPROEX, 1987, p. 11).
\end{abstract}

Esse conceito apresenta a extensão como instrumento de um processo dialético entre a teoria e a prática, promovendo, através da interdisciplinaridade de suas ações, uma visão integrada do social. Tendo por base uma parceria política-pedagógica com a sociedade, Reis (1996) aponta que a extensão, na concepção orgânica-processual, é lócus de formação profissional e de produção do conhecimento, pois produz o saber e forma o discente simultaneamente.

Nesse sentido, o currículo se constitui como instrumento viabilizador e articulador do ensino, pesquisa e extensão “[...] para formar alunos e gerar conhecimentos (...) que venham ao encontro de uma contribuição transformadora e de melhoria das condições de vida, de toda a sociedade brasileira" (REIS, 1995, p. 48). 
Dentro dessa perspectiva, o currículo e a formação inicial transcendem a visão tradicional de ensino. Permitindo-se uma formação integral desses sujeitos, visando a totalidade dos processos históricos e sociais que os constitui, faz-se necessário pensar sobre o modelo tradicional de ensino e as pedagogias hegemônicas atuais.

Para Apple (2006), a hegemonia se refere a "[...] um conjunto organizado de significados e práticas, ao sistema central, eficaz e dominante de significados, valores e ações que são vividos" (p.39). A hegemonia estaria ligada ao processo de tradição seletiva apresentada pelo autor, que seria o ato de selecionar determinados significados e práticas em detrimento de outras, podendo essas serem reinterpretadas. Isso pode ser uma ação estabelecida no currículo, pois ele não é neutro e sim parte de uma tradição seletiva, que confere legitimidade cultural a determinados grupos e a seleção de determinados conhecimentos. Para Sarcristan (2000), “[...] os currículos são a expressão do equilíbrio de interesses e forças que gravitam sobre o sistema educativo num dado momento" (p. 17). O currículo é um espaço de disputa e poder, cultural, política e social, promovendo uma seleção cultural.

Apple (2006) vai dizer que, para a manutenção do controle social, o poder e a cultura dentro do currículo oculto precisam ser estáticos, sendo necessário, cada vez mais, uma justificação que estabeleça limites ideológicos. Dessa forma, dentro de uma lógica positivista, o currículo e o conhecimento estariam dissociados dos sujeitos. $\mathrm{O}$ autor ainda apresenta um conceito de currículo oculto, que seriam "as normas e os valores que são implicitamente, mas eficazmente, ensinados nas escolas e sobre os quais o professor em geral não fala nas declarações de metas e objetivos" (APPLE, 2006, p.127). O tratamento do conflito no currículo é a chave para romper com essa lógica, juntamente com uma consciência crítica a respeito dos objetivos ideológicos e políticos, pois, assim, os educadores podem perceber em suas análises o que passa por eles no currículo.

Ao pensar em uma reflexão crítica do currículo, temos a concepção apresentada por Apple (2006), que diz

Não é "apenas" uma questão educacional, mas inerentemente ideológica e política. Quer a reconheçamos ou não, o currículo e as questões educacionais de cunho mais geral sempre estiveram presentes nas histórias de conflitos de classe, raça, gênero e religião nos Estados Unidos e em outros países (APPLE, 2006, p. 21, grifos do autor). 
Para que se tenha essa consciência crítica do currículo, este não pode estar dissociado de quem pensa e executa. Sacristán (2000) também apresenta um conceito que nos auxilia, o qual o currículo é o "[...] projeto seletivo de cultura, cultural, social, política e administrativamente condicionado, que preenche a atividade escolar e que se torna realidade dentro das condições da escola tal como se acha configurada" (SACRISTÁN, 2000, p. 34). Para se ter um currículo crítico, é importante pensar na articulação entre teoria e prática, concebendo na formação uma vinculação simultânea e reciproca de duas bases que são autônomas, mas também dependentes.

Para Gramsci (1999), a unidade entre teoria e prática se dá pela consciência política, como uma necessidade histórica. Por meio dessa unidade, é possível superar as várias políticas, ou seja, hegemonias, por uma consciência coletiva, orientada por uma práxis transformadora. O movimento de transformação é mais rápido quando as forças práticas se tornam mais eficientes e expansivas e os programas teóricos demonstram a possibilidade de assimilação prática. A fim de

construir, com base numa determinada prática, uma teoria que, coincidindo e identificando-se com os elementos decisivos da própria prática, acelere o processo histórico em ato, tornando a prática mais homogênea, coerente, eficiente em todos os seus elementos, isto é, elevando-a à máxima potência; ou então, dada uma certa posição teórica, no de organizar o elemento prático indispensável para que esta teoria seja colocada em ação. A identificação de teoria e prática é um ato crítico, pelo qual se demonstra que a prática é racional e necessária ou que a teoria é realista e racional (GRAMSCI, 1999, p. 260).

A unidade teoria e prática, constituindo-se no plano do real concreto, é dialética e expressa o movimento das contradições, em que ambos se negam e se contrapõem, essa visão dialética da unidade supera uma visão dicotômica posta historicamente. A unidade teoria e prática fomenta a dimensão política pela práxis, que seria possível pela investigação das condições concretas, pela formulação de uma consciência coletiva.

Enquanto práxis, entendemos que o conhecimento crítico e a análise crítica se dão por uma prática transformadora da realidade, tanto pelo âmbito do conhecimento, quanto pelo âmbito histórico social, rompendo com a visão idealista e hegemônica da classe dominante. Dessa forma, a construção do conhecimento ocorre na práxis e pela práxis, através do processo indissociável de teoria e prática/ação, na qual a perspectiva 
reflexão-ação, ocorre por meio de uma reflexão teórica que gere uma ação transformadora.

\title{
3 O QUE O CURRÍCULO NOS DIZ?
}

O curso de Pedagogia da UnB é ofertado nos turnos diurno e noturno. Os alunos entram no curso por meio do Vestibular e do Exame Nacional do Ensino Médio (ENEM) e saem com formação em licenciatura plena, estando habilitados a exercer a profissão em qualquer área.

A estrutura curricular do curso de Pedagogia, aprovada em 2018, em relação a formação de professores, tem com objetivo

\begin{abstract}
a inserção dos formados para atuar de forma ética e socialmente responsável nesses espaços, contribuindo para a redução das desigualdades sociais e para a consolidação de uma sociedade democrática. Com essa perspectiva, o curso está estruturado de maneira a propiciar a concepção de um programa de formação que estabelece os componentes básicos da formação inicial e continuada, articulando o ensino com a pesquisa e a extensão através da nucleação das atividades em torno de eixos integradores (BRASIL,2018, p. 21$,$) .$
\end{abstract}

O projeto político pedagógico aponta, como missão da faculdade de educação, a função de formar um bom profissional, que seja capaz de intervir na sua realidade e daqueles que estão a sua volta, a proposta possui uma orientação humanística que preconiza uma formação artística, literária, científica e técnica, sendo parte da missão da FE-UnB a produção de conhecimentos inovadores e a disseminação dos saberes pelo ensino e extensão, e pelas diversas formas de disseminação.

O documento, em análise, apresenta ainda os princípios que regem o Projeto Político Pedagógico (PPP) da instituição, sendo eles: autonomia, diversidade, gratuidade, igualdade, indissociabilidade, interdisciplinaridade, liberdade, qualidade, pluralidade, valorização e vinculação. Esses princípios estão ancorados na Constituição Federal de 1988 e na Lei de Diretrizes e Bases da Educação de 1996.

A proposta curricular está estruturada de forma a proporcionar a construção de uma identidade profissional, de uma articulação do ensino, pesquisa e extensão, por uma formação prático-teórica de um profissional autônomo e com atenção prioritária a necessidade da população brasileira. A base docente proposta no currículo se compõe por três dimensões formativas 
Educação - sujeitos, história, sociedade e cultura; Organização do trabalho docente; Profissionalização do pedagogo: gestão, diversificação e sistematização do conhecimento. Além dos componentes curriculares obrigatórios e optativos (disciplinas), as dimensões formativas compreendem os estágios, as atividades de extensão e pesquisa bem como atividades complementares (BRASIL, 2018, p.41).

As dimensões formativas seriam o eixo norteador da formação dos alunos e podem ser ofertadas nas mais diversas áreas do conhecimento e de atuação do pedagogo, segundo o documento são entendidas como atitude metodológica de ensino e aprendizagem. O currículo parte do princípio da flexibilização, como uma totalidade viva e em movimento, que se constitui de forma indissociável da realidade, articulando o conhecimento científico e visando a superação da fragmentação desse conhecimento.

Interessa-nos, neste artigo, pensar o papel e a execução da extensão universitária nesse currículo; no antigo projeto acadêmico, a extensão ocorria por meio dos projetos que se constituíam como eixo nortear do curso. Nessa nova formulação, a extensão está prevista nos estágios curriculares que são desenvolvidos ao longo de toda a graduação. É perceptível que o projeto não apresenta uma concepção clara sobre a extensão universitária, pois sistematiza no currículo a extensão e o estágio como se fossem a mesma coisa, ou desenvolvidas concomitantemente no mesmo espaço, ou seja, durante o estágio. A partir da análise da Resolução n. 7, de 18 de Dezembro de 2018, que estabelece as diretrizes para a Extensão na Educação Superior Brasileira, podemos inferir que as atividades de extensão são:

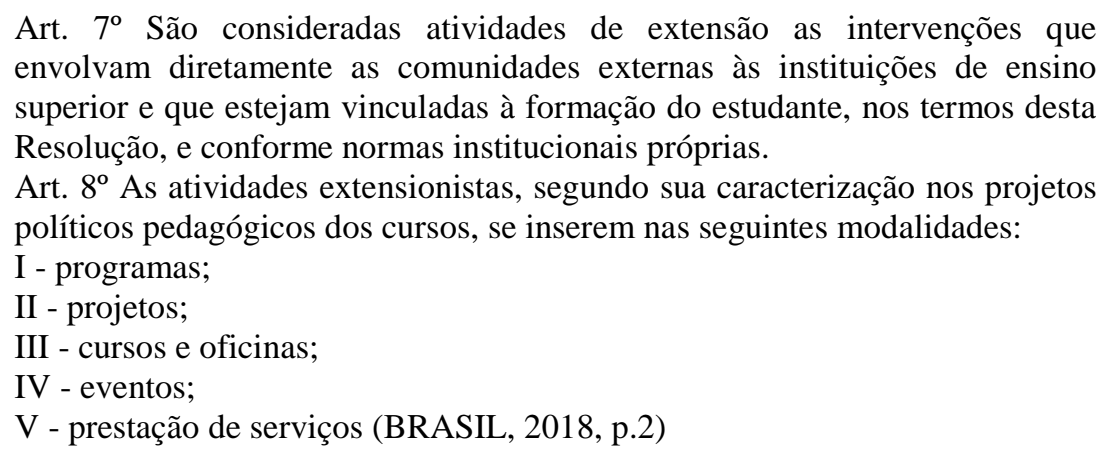

De acordo com as diretrizes da extensão, o estágio não se configuraria como modalidade de atividades de extensão. Contudo, é importante ressaltar que o documento aprovado em 2018 foi pensado, discutido e aprovado antes dessa resolução e, por isso, 
parece associar estágio a extensão, mas em recentes estudos, o Núcleo Docente Estruturante, está atualizando o documento, mediante a legislação atual e sob a coordenação do Decanato de Extensão.

Como o PPP ainda se encontra em fase de implementação e revisão, podemos ressaltar a prevalência de vários programas, projetos e atividades de extensão existentes na Faculdade de Educação e que podem facilmente ser localizados no site da instituição. Essas modalidades ainda serão alocadas no currículo de forma a cumprir a integralização de $10 \%$ da carga horária curricular estudantil em ações de extensão. Esses projetos e programas se orientam pela práxis e pelo princípio da indissociabilidade, numa parceria político-pedagógica com a sociedade que possibilita aos participantes a construção de um movimento práxico, quando assume a concepção orgânica-processual, apresenta por Reis (1996), visando à transformação social. Sacristán vai apontar que

\begin{abstract}
O currículo é uma práxis antes que um objeto estático emanado de um modelo coerente de pensar a educação ou as aprendizagens necessárias das crianças e dos jovens, que tampouco se esgota na parte explícita do projeto de socialização cultural nas escolas. É uma prática, expressão, da função socializadora e cultural que determinada instituição tem (SACRISTÁN, 2000, p.15).
\end{abstract}

A extensão dentro dos projetos e programas se configura em um processo formativo e transformativo de seus participantes, tornando possível a articulação teoria e prática dentro do contexto social e, dessa forma, contribuindo para a formação política. Por essa linha, a extensão, pelo princípio da indissociabilidade e pela práxis, contribui para a formação de uma consciência política.

Faz-se necessário apontar como fragilidade nesse currículo a falta de esclarecimentos da forma como a extensão seria desenvolvida nesses projetos e, principalmente, pela abertura que ele tem de oferta e temática, que deixa livre aos professores a escolha de oferta e não oferta, inclusive por semestre. A questão da escolha de oferta das ações ser do professor pode acarretar na sua não continuidade, causando prejuízo aos alunos, ao passo que seu percurso em determinada temática e projeto pode ser interrompido pela falta de oferta das ações de extensão pelo professor.

A flexibilidade do curso de pedagogia e a visibilidade que a extensão possui nesse curso são caraterísticas que possibilitam "[...] não somente a incorporação da 
participação dos estudantes em atividades de pesquisa e extensão, mas faz com que a organização curricular assuma um novo desenho a partir de uma nova concepção" (FORPROEX, 2006, p.45). O documento Extensão Universitária e a Flexibilização Curricular ainda ressaltam que essa flexibilização traz uma ideia de liberdade e autonomia para que os estudantes possam construir sua identidade, seu caminho e seu currículo.

Importante ressaltar que o projeto político acadêmico do curso precisa ter clareza quanto à concepção de extensão adotada, pois isso determinará a relação entre teoria e prática estabelecida nas ações de extensão, bem como as possibilidades de construção de uma consciência política.

Contudo, no contexto de uma sociedade capitalista que constitui espaços privilegiados para as mais profundas formas de alienação das consciências, a superação desse processo de alienação se dá pela formação de uma consciência política como já evidenciado em Gramsci, com a constituição de intelectuais que, por uma relação dialética entre a objetivação e apropriação da realidade concreta, consigam produzir uma práxis revolucionária. Em Duarte (2008), essa característica ontológica da prática social humana possibilita uma reflexão epistemológica no qual a produção do conhecimento se dá por um sujeito cognoscente numa perspectiva histórico social, por uma produção do conhecimento socialmente novo ou pela "apropriação, pelos indivíduos, dos conhecimentos já existentes, a análise epistemológica precisa caracterizar justamente os elementos que configuram a inevitável historicidade da relação entre sujeito e objeto" (DUARTE, 2008 p. 29). Dessa forma, a formação precisa estar aliada aos processos históricos sociais que constituem o sujeito e a realidade concreta.

Essa visão é reforçada em Cruz (2015), ao considerar que a formação de uma consciência política não se estabelece de forma linear, tão pouco imediata, mas que deve passar pela participação ativa do sujeito em diferentes frentes de luta política. E temos na extensão universitária, na perspectiva orgânica-processual, um espaço de lutas pela efetivação dos direitos sociais, no qual todo ato político é um ato educativo.

A extensão e a formação pautadas pela práxis não ocorrem de forma fragmentada e isolada da realidade dos sujeitos; pelo contrário, constitui um espaço formativo, no qual o ensino-aprendizagem ocorre de maneira mútua, levando em 
consideração a integralidade dos sujeitos e o contexto histórico em que estão inseridos. Entendemos que a contribuição da extensão universitária para a construção da consciência política na formação inicial dos estudantes, dá-se pela relação entre universidade, sociedade e escola, pela unidade teoria e prática, possibilitando a emancipação dos sujeitos para uma transformação pessoal, social e acadêmica, ou seja, a constituição de uma consciência política só é possível pela práxis, por uma formação que possibilite a apreensão dos processos históricos com todas as mediações e contradições inerentes a essa formação.

\section{CONSIDERAÇÕES FINAIS}

O trabalho aqui apresentado buscou analisar, a partir do currículo, a contribuição da extensão universitária para a construção da consciência política na formação inicial dos estudantes do curso de pedagogia da Universidade de Brasília (UnB).

Conseguimos identificar que a extensão se configura na matriz curricular do curso de Pedagogia, principalmente pelos projetos norteadores do curso, que podem se configurar como atividades orientadas de extensão. A formação pelos projetos revela um avanço importante na matriz curricular em relação ao currículo anterior. Esses podem ser ofertados nas mais diversas áreas do conhecimento e de atuação do pedagogo. Dessa forma, é por meio dos projetos que a extensão se oficializa dentro desse currículo, pois se estabelece um espaço de execução dentro do fluxo curricular.

Como fragilidade, em relação a extensão, apontamos para a falta de esclarecimento no currículo quanto à sua oferta nos projetos, tendo em vista que a oferta fica a cargo do professor e pode ser feita por semestre não possuindo necessariamente um caráter continuo.

Por fim, ressalta-se que a proposta na matriz curricular de um currículo aberto e em movimento, dá a liberdade e autonomia para os estudantes escolherem o seu próprio percurso, a partir da escolha das disciplinas optativas, estudos independentes e aprofundamento nas mais diversas temáticas ofertadas nos projetos. Os projetos e os programas de extensão possibilitam aos estudantes uma oportunidade maior de prática e principalmente de práxis pela relação teoria e prática numa perspectiva transformativa.

A formação universitária, ou seja, completa, dá-se pelo princípio da indissociabilidade, na relação de unidade teoria e prática, com o movimento dialético 
entre universidade, escola e sociedade, em uma parceria político-pedagógica, possibilitando a construção de um movimento práxico. E é pela práxis que a extensão contribui para a formação de uma consciência política, através de um espaço de retroalimentação entre teoria e prática e realidade concreta, no qual os participantes podem ter uma atuação transformadora e completa, alcançando a emancipação.

\section{REFERÊNCIAS}

APPLE, M. W. Ideologia e Currículo. 3. ed. Porto Alegre: Artmed, 2006.

BRASIL. Lei $\mathrm{n}^{\mathbf{0}}$ 13.005, de 25 de junho de 2014. Aprova o Plano Nacional de Educação (PNE) e dá outras providências. Diário Oficial da União [da] República Federativa do Brasil, Brasília, 2014.

Projeto Político Pedagógico do Curso de Pedagogia - PPPC. Brasília/DF: Universidade de Brasília, Faculdade de Educação, 178 páginas, 2018.

Resolução CNE/CES No 7, de 18 de dezembro de 2018. Diretrizes para a Extensão na Educação Superior Brasileira. Brasília - DF, 2018.

CRUZ, C. A. M. Qual o papel da formação teórico-política na construção da consciência de classe? Textos e Contextos, v. 14, n. 2, p. 282-290, 2015.

DUARTE, N. Sociedade do conhecimento ou sociedade das ilusões? quatro ensaios crítico-dialéticos em filosofia da educação. I. ed., Campinas, SP: Autores Associados, 2008.

FORPROEX. I encontro de pró-reitores de extensão das universidades públicas brasileiras. Universidade de Brasília-UnB, Brasília, 1987.

Extensão Universitária e a Flexibilização Curricular. Fórum de PróReitores de Extensão das Universidades Públicas Brasileiras. Porto Alegre: URGS; Brasília: MEC/SESu, 2006.

Política Nacional de Extensão Universitária. Manaus, 2012.

GRAMSCI, Antônio. Cadernos do Cárcere. v.1. Edição e tradução: Carlos Nelson Coutinho. Rio de Janeiro: Civilização Brasileira, 1999.

REIS, R. H. O currículo enquanto instrumento viabilizador da articulação-ensinopesquisa-extensão. Caderno de Extensão Universitária, Rio de Janeir.o, v. 04, n. 1995.

. Extensão Universitária: Conceituação e Práxis. I Fórum de Extensão da UDESC. UDESC, Florianópolis, 1993 
Histórico, tipologia e proposições sobre a extensão universitária no Brasil. Revistas Linhas Críticas, BRASÍLIA, v. 02, n. 1996.

SACRISTÁN, J.G. O currículo: uma reflexão sobre a prática. 3.ed. Artmed. Tradução de Ernani F. da F. Rosa. 3. ed. Porto Alegre: Artmed, 2000. 